Swyer, by R. Doll and M. P. Vessey, and by A. Klopper, detail very fully the risks of oral contraceptives. But the conclusion they draw is unanimous. The risks of systemic contraceptives are much less than the risks of pregnancy. The alternatives to oral contraceptives have, on the average, a higher failure rate and carry other disadvantages. The most reasonable conclusion, therefore, is that practitioners should weigh the pros and cons of different methods for each individual patient. Steroidal contraceptives are still the right treatment for many patients, probably for the majority, but research continues into equally efficient and convenient alternatives. Much of the material in the Bulletin is devoted to consideration of them, and some seem promising.

Steroidal hormones act as contraceptives by offering a greater or less degree of endocrine insult. For this reason alone, whatever is done to reduce their toxicity, there is much to be said against their use on a population scale for long. Some of the articles in the Bulletin point the way to alternative means of contraception. If one accepts that the best method is one which, while as convenient as oral medication, is wholly effective and does not involve extensive alteration of the endocrine milieu interieur, there may be something to be said for attempts to control the life of the corpus luteum. During pregnancy the conceptus overrides the normal mechanism of the menstrual cycle and prolongs the life of the corpus luteum. Herein lie two possibilities. We can either block the signal from the conceptus which prevents normal involution of the corpus luteum, or we can try to imitate whatever biological signal normally causes the corpus luteum to involute and precipitate the menstrual period. But here is the difficulty. As L. E. A. Rowson points out, in a section on the evidence for luteolysin, the evidence that some substance from the uterus terminates the life of the corpus luteum in the sheep, pig, and cow is overwhelming. But we do not know what determines the lifespan of the corpus luteum in the human, and it is unlikely to be a simple uterine luteolytic effect. If we did know what the signal was and could imitate it, we could impose a normal menstrual cycle regardless of the existence or otherwise of an early pregnancy.

The editors of the Bulletin have rightly chosen not to concentrate entirely on the preventive aspect of fertility but have included articles by A. C. Crooke and by P. M. F. Bishop on the treatment of infertility by induction of ovulation. It is a curious irony that these two aspects of fertility should be closely linked. Indeed if we could control the lifespan of the corpus luteum it would do much to promote the treatment of infertility.

\section{Bundle Branch Block}

The clinical implications of delayed interventricular conduction in an otherwise asymptomatic patient may be difficult to assess. A general practitioner might well wonder what sort of prognosis to attach to an electrocardiograph report of right or left bundle branch block (B.B.B.)

Unfortunately, the articles published on this subject are rather confusing. Many retrospective studies on patients with right or left B.B.B. come from cardiac units. The patients seen in these departments are referred largely because of cardiac symptoms or signs, so conduction defects are more likely to be associated with frank organic heart disease. This might well explain the very poor prognosis of B.B.B. reported from some centres.' ${ }^{\prime}$ Furthermore, diagnostic methods in cardiology have improved greatly during the last decade, and patients considered to have isolated "idiopathic" B.B.B. ten years ago might no longer be viewed as such now.

Knowledge of the usual anatomy of cardiac conduction tissue is helpful in understanding this problem. ${ }^{2}$ The right bundle leaves the main bundle of $\mathrm{His}$ as a single discrete structure and runs some way before splitting up to supply the right ventricular mass. It follows, therefore, that a single small but crucially located lesion could completely interrupt conduction, resulting in right B.B.B. In contrast, the left bundle consists of a series of radiating fine structures directly branching from the main bundle. Only a relatively widespread lesion affecting most of the widely dispersed branches would result in left B.B.B.

In most cases the electrocardiographic detection of B.B.B. merely provides supplementary information in the presence of obvious heart disease. In these circumstances the prognosis of the B.B.B. is that of the underlying cardiac disorder. A careful search is most likely to detect coronary artery disease, hypertension (or a combination of the two), rheumatic heart disease, or cardiomyopathy. "s Elderly patients in particular are likely to have an important underlying organic basis for their conduction disturbance. Indeed, a pattern of left B.B.B. may completely conceal the electrical changes of frank cardiac infarction." In addition, patients with intermittent complete heart block and Adams-Stokes attacks may present with a history of syncope and electrocardiographic evidence of right B.B.B. only: Clearly, the prognosis of apparently isolated B.B.B. in an elderly subject should be guarded-and particularly so in the presence of left B.B.B.; the chances of more serious organic heart disease are high if not immediately apparent.

It is equally clear, however, that there is a low incidence of right or left B.B.B. among an otherwise healthy, non-patient population. $^{\times 9}$ Though commoner in subjects over 35 years of age, this type of conduction disturbance has been reported in all age groups. ${ }^{10}$ It is this situation which faces the practitioner with a dilemma. Fortunately, follow-up studies on asymptomatic subjects with incidentally detected B.B.B. reveal an excellent prognosis. ${ }^{4}$ It is justifiable to strongly reassure such a subject rather than court the risk of undue cardiac invalidism, even though an accurate prognosis in an individual case is rarely possible.

Campbell, M., British Heart fournal, 1969, 31, 575.

- Hudson, R. E. B., Cardiovascular Pathology, vol. 1, p. 111. London, Arnold. 1965.

Johnson, R. P., Messer, A. L., Shreenivas, and White, P. D., American Heart fournal, 1951, 41, 225.

Bauer, G. E., Australasian Annals of Medicine, 1964, 13, 62.

Harvey, W. P., Segal, J. P., and Gurel, T., Progress in Cardiovascular Diseases, 1964, 7, 17

Scott, R. C., American Heart fournal, 1965, 70, 813.

Harris, A., Bluestone, R., Busby, E., Davies, G., Leatham, A., Siddons, H., and Sowton, E., British Heart fournal, 1965, 27, 469.

Rodstein, M., Gubner, R., Mills, J. P., Lovell, J. F., and Ungerleider, H. E., Archives of Internal Medicine, 1951, 87, 663.

${ }^{9}$ Katz, L. N., and Pick, A., Clinical Electrocardiography. Philadelphia, Lea and Febiger. 1965.

Hiss, R. G., and Lamb, L. E., Circulation, 1962, 25, 947. 